Lepr Rev (2000) 71, 420-421

\title{
Editorial
}

\section{IMPLEMENTING GUIDELINES FOR SOCIO-ECONOMIC REHABILITATION}

Social and economic rehabilitation of people affected by leprosy is now a major priority. Social and economic rehabilitation (SER) programmes that benefit people affected by leprosy already exist in many countries around the world. They differ in content and in context. While poverty is a common factor, they face different challenges and opportunities. Can guidelines be of help?

The Guidelines for Socio-economic Rehabilitation reproduced in this issue have sought to identify the broad principles and approaches that have been found to work in existing, successful SER programmes. These guidelines provide individuals and organizations with the information and tools they need to ensure project activities are appropriate and of real benefit to those in need. The guidelines provide sensible help and ideas for those starting a new project as well as for those already involved in SER activities. The guidelines will prove to be practical and effective, since the contents have been distilled from the contributions and experience of those actively involved in the field.

Leprosy control programmes are increasingly recognizing the importance of SER as a vital aspect of leprosy work. There is now the opportunity to develop new areas of expertise. New skills are needed, new approaches have to be tried, and new alliances have to be made. It is important to seize the opportunity and adopt new approaches that benefit those in need and enhance their dignity.

It is important to reflect on the experience of others before applying their conclusions in a new situation. These guidelines bring together a wealth of experience in one document. They will generate new ideas, encourage new approaches and promote the sharing of information among all those involved in the field. They also serve as a source of personal encouragement to all those seeking to bring an improved quality of life to those whose lives have been affected by leprosy.

The development and publication of these guidelines is an important step forward, but it is only the first step. The next steps are the dissemination and implementation of the guidelines, these are two different aspects. Dissemination is a logistical challenge as those who would benefit from them work across the globe and often in remote areas. Follow-up of previous guidelines in leprosy often reveals the field workers at grass roots level have no access to these publications. This can be for a number of reasons; they get held up at some place, there 
are no resources to post them out within countries and they are left on shelves or put in libraries and never used.

However, dissemination is not implementation. Implementation is a further step that requires that the guidelines are read and that they result in appropriate behaviour change. Guidelines have been developed and disseminated for a wide range of health and medical programmes and they all have the same challenge of implementation. There needs to be advocacy by funding organizations, programme managers and opinion leaders for the guidelines to be implemented. This can include workshops and educational seminars, target setting or the requirement that the guidelines are used for programme planning and reporting. The publication of the guidelines in this special issue of Leprosy Review along with a series of papers and reports is aimed at promoting the use of these guidelines in field programmes. There also needs to be a felt need, a demand for the guidelines from field staff and those who do not have access to a copy should contact ILEP immediately ${ }^{1}$ to request a copy.

The authors of the guidelines on socio-economic rehabilitation are to be congratulated on the development and production of these SER guidelines. However, this is only the first step; the next step is to ensure dissemination of the guidelines to all relevant field staff. Following the dissemination is the implementation of the guidelines to improve the quality and quantity of socio-economic rehabilitation. The final step will be to evaluate their effectiveness.

\section{Reference}

1 The Guidelines on Socio Economic rehabilitation can be obtained free of charge from ILEP. Requests can be sent to ILEP 234 Blythe Road, London W14 OHJ, UK. Tel. +44 (0)20 7602 6925, Fax +44 (0)20 7371 1621, e-mail ilep@ilep.org.uk. Orders can also be made directly from the TALMilep pages of the ILEP Web site www.ilep.org.uk

Department of Public Health

W. CAIRNS S. SMITH

University of Aberdeen

Foresterhill

Aberdeen AB9 2ZD

$U K$ 